Check for updates

London, UK

Cite this as: BMJ 2020;370:m2838 http://dx.doi.org/10.1136/bmj.m2838 Published: 20 July 2020

\section{Caring for vulnerable patients during the pandemic: the consultant ophthalmologist}

\section{Kin Sheng Lim speaks to Helen Jones about dealing with covid-19 and his own role models Helen Jones}

Covid-19 has had a huge impact on the work of Kin Sheng Lim, who is clinical lead in the glaucoma service at Guy's and St Thomas' NHS Foundation Hospital Trust.

"A lot of my patients are elderly and we really don't want to bring them into hospital unless we have to," Lim says, "But at the same time, glaucoma is one of those conditions where you have to physically see patients and measure pressure in the eye-there are no shortcuts for that."

Lim says he and his team have been trying to minimise the contact time that they have with patients in clinic and reduce the frequency of follow-ups. "It worries me that some patients are too frightened to come into hospital," he says. "Glaucoma damage is irreversible, and it's the second biggest cause of blindness in Europe.”

Despite the current difficulties, Lim is keen to encourage medical students to think about a career in ophthalmology. "Try and get as much exposure to ophthalmology as possible during medical school-spending more than a two week attachment in an ophthalmology department would certainly help," he advises.

Lim's own journey into ophthalmology began in medical school, although it wasn't his first choice of career. "I wanted to do cardiothoracic surgery," he says. However, a three month stint working in the specialty during his elective taught him otherwise. "I actually found it quite tedious," Lim says.

It was working alongside an ophthalmologist during his final clinical year that got him into the specialty. "He described how cataract surgery only takes 20 minutes to perform but can transform someone's life. That was it. I was completely hooked," Lim says. "Cardiothoracic surgery takes four or five hours and people don't always get better-so I switched to ophthalmology."

During his career Lim has had two role models. The first is Peng Tee Khaw, consultant ophthalmic surgeon at Moorfields Eye Hospital in London. "He would provide clinical service at the highest level and produce world class research at the same time-and that's what I strive for," Lim says.

The second is Richard Brubaker from the Mayo Clinic in Rochester, Minnesota, who died in 2019. "I spent a year in 2004 as a postdoctoral fellow under his supervision," Lim says. "He was an incredible figure in the world of glaucoma aqueous dynamic research and taught me everything about the subject. He inspired me to start my own aqueous dynamic lab on my return to London.”
Lim's own research focuses on glaucoma. "When I finished being a senior house officer I needed a research project to enable me to do a postgraduate degree," he explains. "The only project available at the time was in glaucoma, so I spent two and a half years carrying out research. At the end of it I became an expert in one small aspect of glaucoma-which pushed me to learn about other areas."

Lim now combines clinical work with his role as ophthalmology departmental lead for research. "I manage a big clinical service and a research unit employing 15 to 20 people in each," he says. "It takes up equal amounts of time."

\section{Nominated by Pouya Alaghband}

"I moved from Iran to the UK and I had been practising as a GP, but my aspiration was to become an ophthalmologist. I began my journey in ophthalmology as a research fellow and Mr Lim gave me the opportunity to pursue my dream.

"I remember him single-handedly covering the glaucoma service at St Thomas' Hospital and overseeing an expanding and busy service.

"He has participated in several landmark ophthalmic clinical trials and managed to recruit the highest number of cases in many of these studies. He also set up the ophthalmology clinical trials unit and is the head of ophthalmology research and development at Guy's and St Thomas' and an associate professor in ophthalmology. "I am indebted to him for my career-he's my hero." Pouya Alaghband is a consultant ophthalmologist at York Teaching Hospital NHS Foundation Trust 